\section{Caries detection and diagnosis, sealants and management of the possibly carious fissure}

\author{
C. Deery ${ }^{1}$
}

VERIFIABLE CPD PAPER
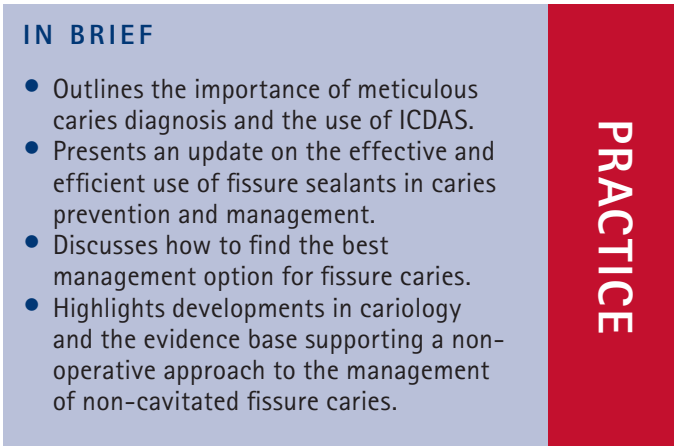

The diagnosis and management of 'stained' or possibly carious pits and fissures is a difficult clinical problem. Historically, clinicians have restoratively intervened at an early stage because of concern that caries will progress unless completely removed and a restoration placed. However, this approach is destructive of tooth tissue and in the longer term may compromise the tooth as it enters the restoration re-restoration cycle. This paper aims to update the reader on developments in sealant technology and the use of sealants in caries prevention and management with an emphasis on the options available to manage the questionable fissure.

\section{INTRODUCTION}

Further advances in the understanding of the histopathology of caries have altered the understanding of caries. Caries is driven by the biofilm on the surface of the lesion; if all the dental plaque is removed or the carious lesion is isolated from the biofilm then caries will arrest. Although it has long been recognised that enamel can remineralise it has only recently been appreciated that the dentine-pulp complex is capable of significant repair, which means the clinician can leave affected dentine. Therefore the approach to the management of caries should focus on biological rather than restorative management within an overall caries risk reduction programme.

This process should be supported by an evidence-based staging of caries, from early enamel caries to pulpal involvement, using a validated and reliable meticulous caries examination system to detect and diagnose caries (ICDAS), supported by radiographs and the treatment option decision informed by a caries risk assessment.

${ }^{1}$ Professor of Paediatric Dentistry, Unit of Oral Health and Development, School of Clinical Dentistry, University of Sheffield, Claremont Crescent, Sheffield, S10 2RN

Correspondence to: Professor Chris Deery Email: c.deery@sheffield.ac.uk; Tel: 01142717974

\section{Refereed Paper}

Accepted 17 April 2013

DOI: $10.1038 /$ sj.bdj.2013.525

${ }^{\circledR}$ British Dental Journal 2013; 214: 551-557
Pit and fissure sealants are highly effective at caries prevention, reducing the incidence of dentinal caries over a four year period by greater than $50 \%$. Forty years of research clearly demonstrates that sealants can be used therapeutically over noncavitated carious lesions. Therefore when dealing with occlusal caries the clinician should follow the 'if in doubt seal' management strategy, as the evidence base clearly indicates that this will be effective and in the best interest of the patient.

A common diagnostic dilemma is the management of the occlusal fissure where the diagnosis of the existence of caries, or more properly, of progressing caries is uncertain. In clinical parlance these occlusal surfaces are often referred to as 'stained fissures'. This diagnostic problem can occur with any age of patient but occur more frequently with young patients. ${ }^{1}$ Figures 1 and 2 are examples of two possibly carious occlusal surfaces.

The understanding of caries has advanced greatly over recent years and it is now understood that caries is a dynamic process with phases of demineralisation and remineralisation. ${ }^{2}$ Depending on the balance between these two processes a carious lesion may either regress, progress or stay static. Together with this greater understanding of the disease process there have been advances in diagnostic methods and even greater advances in materials permitting a far less destructive approach to treatment.

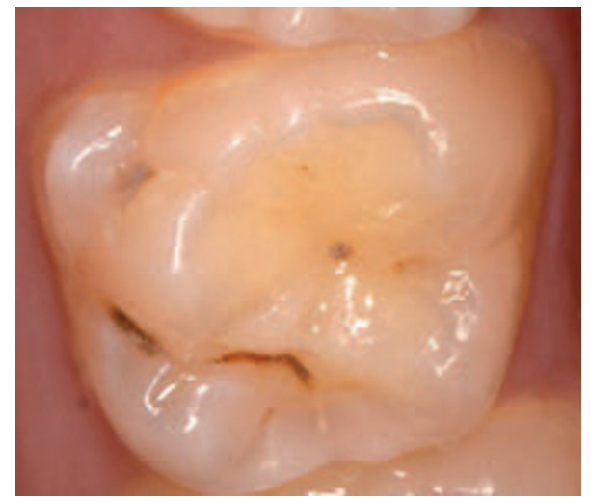

Fig. 1 Possibly carious occlusal fissure upper right first permanent molar (tooth 16)

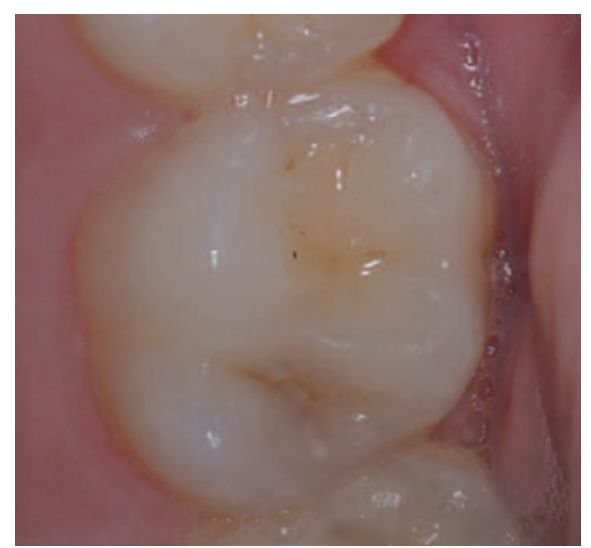

Fig. 2 Possibly carious occlusal fissure upper right first permanent molar (tooth 26)

Dental caries and its sequelae remains a significant public health problem. Despite declining levels of disease the 2003 Children's Dental Health Survey reported 19\%; 43\% and 57\% of 8- 12- and 15-year-olds to have obvious decay experience respectively. ${ }^{3}$ 
If a tooth is restored unnecessarily this involves the patient having the discomfort (however mild) of the local anaesthetic, caries removal and restoration placement, together with the potential opportunity costs of, for example, time off school. Perhaps more importantly in the long term the tooth will enter the restoration re-restoration cycle, with replacement restorations getting ever larger, until they eventually compromise the tooth in the long term. ${ }^{4}$ Furthermore, it is simply unacceptable to cause iatrogenic damage to the teeth.

Modern pit and fissure sealants (sealants) were developed in the late 1960s and there is strong evidence that this relatively simple operative intervention is effective in the management of caries. The Cochrane review from Ahovuo-Saloranta et al. reported that at 4,854 months after sealant application there is a greater than $50 \%$ reduction in caries on occlusal surfaces compared to unsealed teeth. ${ }^{5}$ This underestimates their true effectiveness because sealants should be maintained and repaired when defective and if this is done the caries preventive effect is even greater. ${ }^{6}$

This paper aims to update the reader on developments in sealant technology and the use of sealants in caries prevention and management with an emphasis on the options available to manage the questionable fissure. It will discuss how advances in the understanding of the histopathology of caries have altered our understanding of caries. In addition this paper will examine the need for adequate logical evidence-based staging of caries from early enamel caries to pulpal involvement and how this, as part of a caries risk reduction programme, is used to control the caries present.

\section{THE CARIOUS PROCESS}

The carious lesion in enamel consists of four zones: the translucent zone, the body of the lesion representing areas of demineralisation, the surface zone and the dark zone representing areas of remineralisation. ${ }^{7}$ The uncavitated enamel lesion is in a dynamic balance between demineralisation and remineralisation. Whether the balance tips one way or the other depends on the oral environment, something which the individual or in the case of a child the individual and carers can influence markedly.

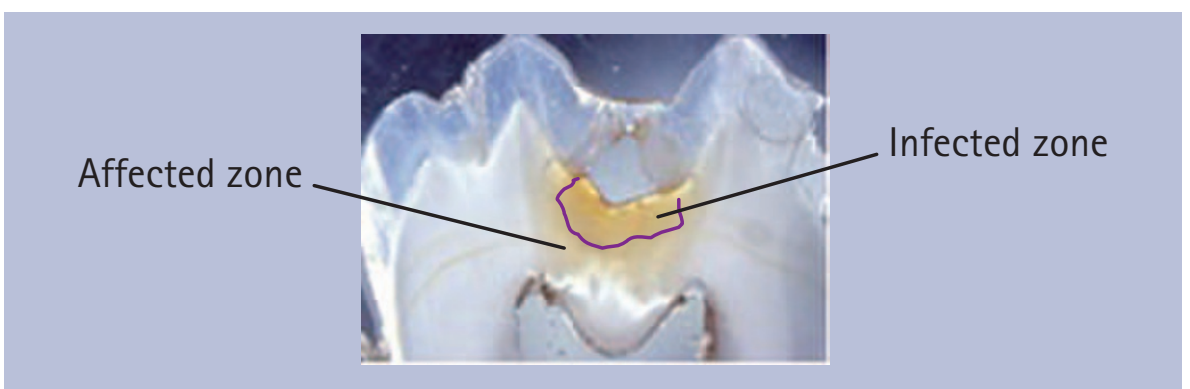

Fig. 3 A section of dentine carious lesion, with the infected and affected zones of carious dentine identified. (Background image used with kind permission of eDen)

Traditionally, dentine caries is histologically considered to consist of four zones, however it is probably much more clinically relevant to think of two zones: the infected layer and the affected layer (Fig. 3). ${ }^{8}$ The infected layer is seriously denatured with high levels of bacterial invasion and therefore is not capable of repair. On the other hand, although still infected, the affected layer is capable of repair should the caries be arrested.

It is also now understood that carious lesions are only significantly infected once the carious lesion extends into the middle third of dentine and that infection levels increase markedly once a lesion has cavitated. ${ }^{9}$ The consequence of these statements is that traditional complete caries removal down to hard dentine is overly destructive. ${ }^{10}$

Key to the progression of caries in children or adults is the presence of a cariogenic dental plaque or biofilm on the tooth surface. ${ }^{11}$ If there is no cariogenic biofilm present the caries will arrest whether it is in enamel or dentine. Figure 4 shows advanced dentinal carious lesions in the primary dentition, which have arrested because in addition to less frequent exposure to carbohydrates in the diet the surfaces are being regularly cleaned preventing the establishment of a cariogenic biofilm, which if left undisturbed would drive the caries forward.

The whole understanding of the ability of the dentine pulp complex to repair is undergoing review, leading to an understanding that the dentine and pulp complex is not passive in response to a carious attack but mounts a defence with multiplying of neural tissue, migration of immunological cells, as well as the more recognised production of secondary and tertiary dentine. Therefore the dentist can work with the pulp in a biological manner taking

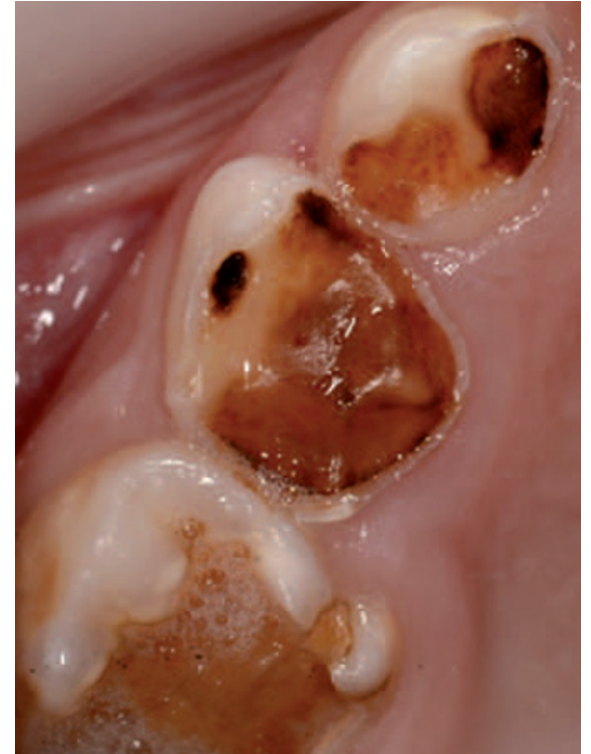

Fig. 4 Carious lesions in primary teeth which have arrested (lesions glossy, dark and hard to blunt probing) due to the absence of a cariogenic biofilm

the opportunity to leave large amounts of tooth tissue that would previously have been removed. It is on this basis that treatments involving indirect pulp capping and stepwise excavation are based. ${ }^{12}$

At present there is no way of knowing from a one off examination whether a carious lesion is progressing, regressing or remaining stable. Practitioners can use a caries risk assessment to help inform this decision but it remains an educated guess and in the light of which a need to develop valid and reliable methods for caries risk assessment has been identified. ${ }^{13}$ Current caries risk assessment tools are based on factors such as previous disease, socioeconomic status, fluoride use and medical history. ${ }^{14-16}$ Although valid at a patient level, these tools cannot predict caries activity at the individual tooth or surface level, with sufficient reliability.

One caveat should be considered when considering these developments in the understanding of the carious process and 


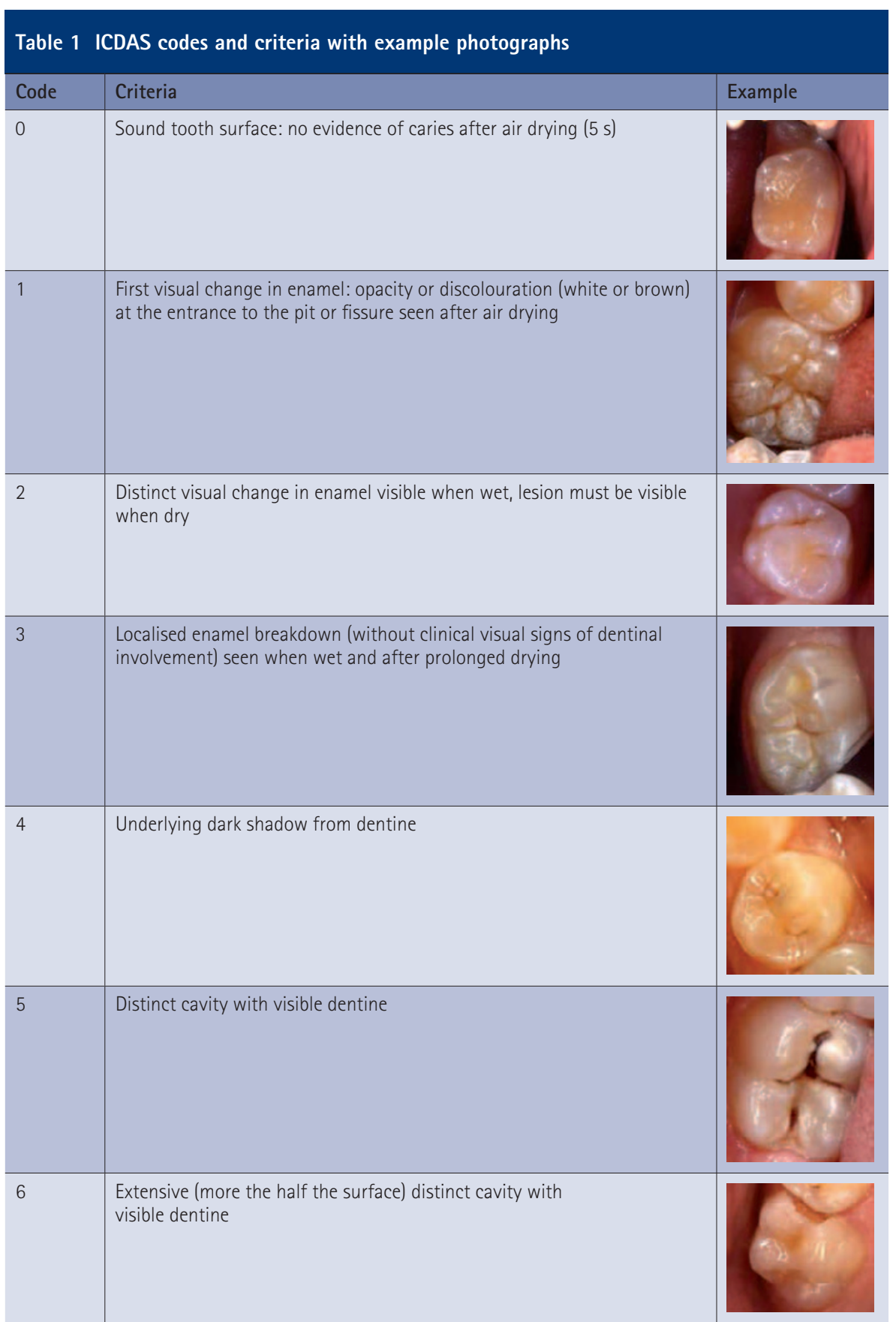

that is that the majority of the research has been conducted on adults. When considering children and adolescents the carious process may be more active and aggressive. This is one argument put forward to suggest a more interventionist restorative approach to caries management in young patients, be that minimal or conventional intervention. A longitudinal study conducted in Scandinavia with adolescent subjects reported that only $9 \%$ of outer dentine lesions, the majority of which were found in the occlusal surface of first molars, progressed to inner dentine lesions in a median time of 1.2 years. ${ }^{17}$ As these teeth had received no active treatment to arrest the caries this relatively small number of lesions progressing perhaps indicates that there is not any more rapid caries progression in adolescents and therefore this is not a great concern.

\section{THE CARIES MANAGEMENT CYCLE AND ICDAS}

The concept of the caries management cycle that manages caries at the patient and tooth level has recently been proposed..$^{18}$ This has, at its centre, the aim to preserve tooth tissue whenever possible. This is achieved by:

- Patient assessment

- Clinical assessment, including dental history, biofilm status and staging of the carious lesions present

- Synthesis of findings and diagnosis.

Leading to management of overall risk status via prevention, non-operative/ surgical management of initial carious lesions, minimal restorative care, review and monitoring.

At the core of management is the staging of carious lesions detected, through enamel caries to pulpal involvement, so that they can be appropriately managed. Therefore the identification of caries consists of two stages the detection of an alteration from normal tooth structure followed by a diagnosis of the depth and activity of the caries present, some would also argue that there is also a synthesis stage where this information is united with other factors such as caries risk status leading to a decision as to the best management or treatment option. ${ }^{19}$ There are a number of methods and toolkits proposed for meticulous caries diagnosis but the one supported by the greatest amount of research evidence is the International Caries Detection and Assessment System (ICDAS). ${ }^{19,20}$ This paper will concentrate on the clinical primary caries codes, as this is of most relevance to the possibly carious fissure. The ICDAS primary caries codes consist of seven codes that stage the surface from sound to extensive decay (Table 1). The clinical appearance correlates with the histological status of the lesion and therefore is linked to appropriate management option selection be that preventive or restorative. What meticulous systems such as ICDAS permit is the identification and recording of enamel caries as well as the traditional recording of dentinal caries, promoting a preventive philosophy to care from the outset. Although the system can appear complicated and time consuming initially this is not the case and it has been demonstrated to be applicable to and function well in primary dental care as well as the research epidemiological environments. ${ }^{21}$

The use of a probe to detect the presence of a 'sticky' fissure plays no part in the detection and diagnosis of occlusal caries, a probe sticking just means it fits the fissure well and does not improve the validity of the examination ${ }^{22}$ and in fact can cause iatrogenic damage by destroying 
the architecture of a demineralised enamel lesion $^{23}$ or by inoculating the fissure with cariogenic bacteria. ${ }^{24}$

Although meticulous clinical diagnosis provides a great deal of information this must be supported by bitewing radiographs as these add to the accuracy of the diagnostic process and together with the staging offered by the clinical examination provide comparison of lesion activity over time. ${ }^{25}$ Figure 5 is the bitewing radiograph of the tooth seen in Figure 1 and Figure 6, similarly for Figure 2. It can be seen how these add to the diagnostic information available to help inform the treatment plan. In Figure 4 there is no radiolucency in dentine while in Figure 5 there is.

Other diagnostic aides have been developed all of which assist with caries diagnosis. These include electrical impedance devices, fluorescence methods, fibre optic transillumination and magnification. However, whether these have any advantage over meticulous visual examination supported by radiographs is debateable. ${ }^{26}$ Of these methods, laser fluorescence (DIAGNOdentKaVo Dental GmbH Biberach, Germany) is the most readily available in practice and offers the greatest potential benefit. ${ }^{27}$

Therefore the clinician needs to gather and record as much information as possible to inform the treatment decision and to permit lesion monitoring. This is particularly the case when considering possible non-cavited caries on pits and fissures. This leads to the question what role do sealants have in managing occlusal caries?

\section{SEALANTS}

Sealants are used preventively (stopping the initiation of caries) or therapeutically (arresting the progression of either enamel or dentine caries). A number of materials are used as sealants including bis-GMA resin, glass ionomer, compomer and flowable composite resin. Of these, bis-GMA resin and glass ionomer are the most commonly used as the other materials offer no advantage over these two materials. ${ }^{5}$ Figure 7 shows a lower first permanent molar sealed with a resin sealant. Resin sealants provide superior caries prevention than glass ionomers if they are retained. ${ }^{5}$ Resin sealants rely on adequate isolation during placement

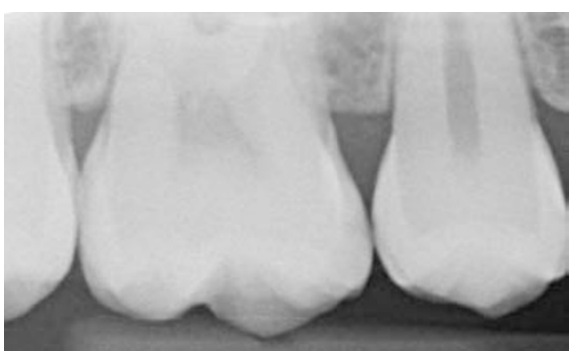

Fig. 5 Bitewing radiograph of upper left 6 (26) seen in Figure 1. Although there is mesial enamel caries the tooth appears sound occlusally

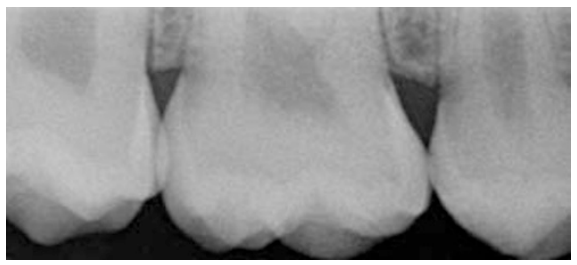

Fig. 6 Bitewing radiograph of upper right 6 (16) see in Figure 2, suggesting the presence of dentine caries in the occlusal palatal fissue

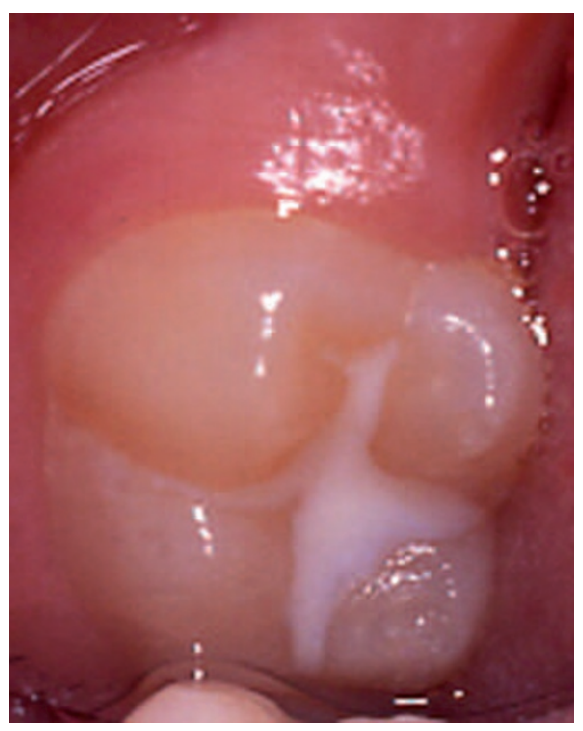

Fig. 7 A sealant on a lower right first molar (tooth 46)

particularly between the drying of the etched enamel surface and curing of the resin. Glass ionomers do not require etching of the surface before placement and will withstand some salivary contamination during placement, and are therefore of use when isolation is an issue in situations such as partially erupted teeth or limited patient cooperation. ${ }^{28}$ Figure 8 shows a glass ionomer sealant placed on a partially erupted first permanent molar. It is also suggested that the fluoride release from glass ionomer provides protection even when the glass ionomer sealant is lost, although if this is clinically valuable it has not been proven. ${ }^{29}$

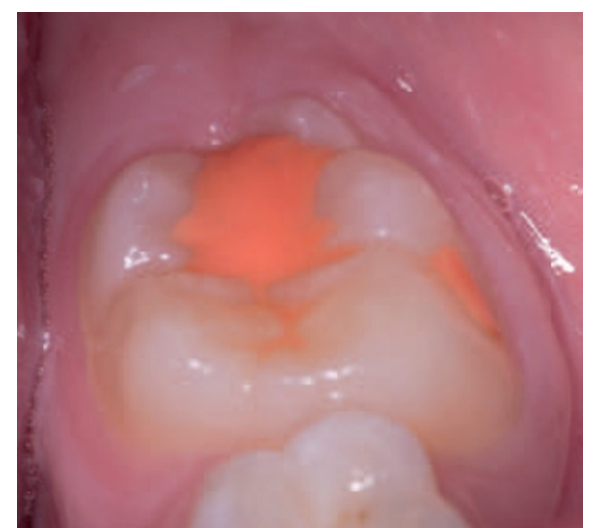

Fig. 8 Glass ionomer selant on a partially erupted lower left first permanent molar (tooth 36). (With kind permission of and thanks to Dr Bhupinder Dawett)

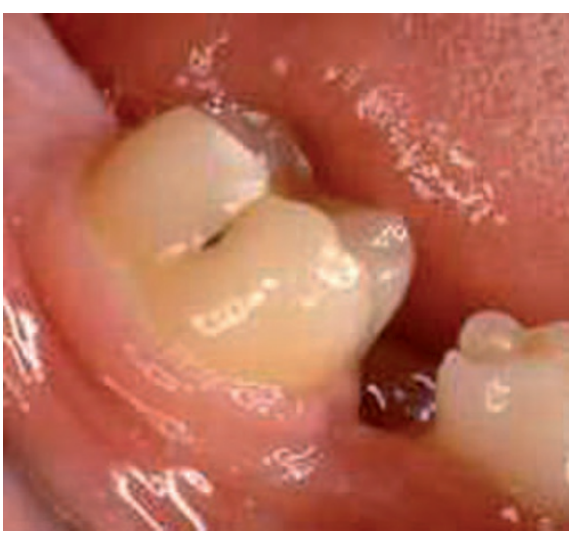

Fig. 9 A buccal pit in a lower right first permanent molar (tooth 36), which would benefit from having been sealed

The protocol for placing a resin sealant is well understood but with developments in materials there have been some innovations over recent years.

1. Provided there are not significant amounts of plaque present there is no need to clean the tooth surface as the acid etching will remove the plaque present ${ }^{30}$

2. The surface should be etched for 2,030 seconds with 35\% phosphoric acid

3. This is followed by washing for 20 seconds and drying until the surface appears frosted

4. The resin is then applied with an instrument rather than a brush as this reduces the risk of air bubbles and makes the resin easier to control (in the author's experience)

5. Although autopolymerising materials are available most operators opt for the advantages of the demand set of light cured materials

6. The sealant is then checked for adequacy and retention. 
It is vital that adequate isolation is maintained during sealant placement, especially between stages three and five. The highly active etched enamel surface can be contaminated by as little as 0.5 seconds of exposure to salivary proteins, thus compromising the bond to the hydrophobic resin. ${ }^{31}$ The use of an enamel and dentine bonding agent has been advocated following stage three, as this can counteract mild contamination but offers no advantage if the enamel has not been contaminated. ${ }^{32}$ However, this lengthens the duration of the procedure and makes salivary contamination more likely especially in those patients where this is already a concern. Overall it is probably preferable to use a glass ionomer material in these situations rather than a bonding agent and resin.

Non-rinse conditioning systems enable composite to enamel bonding without previous phosphoric acid etching of the enamel surface. The etch-and-rinse phase is no longer required, which reduces clinical application time and also reduces the risk of making errors during application and manipulation. It is also possible that this technique is more forgiving of mild salivary contamination. These systems are designed for use on a cut surface. They do not have a sufficiently low enough $\mathrm{pH}$ (at approximately two) and their application time is too short to remove the plaque present in the fissure system and adequately etch the enamel. ${ }^{33}$ Therefore with current materials non-rinse conditioning agents are not an option to replace conventional etching before sealant application but this is likely to change in the future.

The 2003 Children's Dental Health Survey reported that $22 \%$ of 12-yearold children had a sealant present. ${ }^{3}$ The prevalence of caries is skewed, with a minority of children and adolescents having the majority of the disease and although the most caries prone sites are the occlusal surfaces of molars this does not mean that all molars in all children should be sealed. In order to effectively and efficiently use sealants they should be targeted at the individual and and tooth sites likely to develop caries, which should be based on a risk assessment. As well as occlusal surfaces, buccal and palatal pits should also be considered for sealing. Figure 9 shows a buccal pit that would have benefited from sealing. The occlusal surface of the lower first premolar is very caries resistant because of its morphology and therefore sealants are rarely indicated for these teeth. The evidence suggests that sealants are not applied in targeted fashion but rather that some dentists seal teeth and others do not, regardless the remuneration system and therefore the children receiving sealants are not the ones who would benefit most from their application. ${ }^{34}$

\section{SEALING IN CARIES}

Despite the advances in the techniques and adjuncts available to assist with caries detection and diagnosis it still presents a difficult problem with recognised variation in inter- and intra-examiner decisions, which have significant consequences for treatment provision and the dental health of the patient.

A number of prospective trials have examined the effect of sealing over caries, using clinical, radiographic and bacterial sampling techniques to validate their findings. ${ }^{35-44}$ These studies all suggest that caries progression slows or arrests under sealants. The five-year study from Going et al. monitoring sealed carious lesions, which included bacterial sampling, reported 89\% reversal from caries to non-carious, with all control (non-sealed) sites remaining carious. ${ }^{37}$ The benchmark 9 year study of composite and sealant placed over dentine caries, using clinical and radiographic evaluation, has demonstrated the arrest of the carious process in 63 of the 75 teeth available to follow-up. ${ }^{43}$ It also should be remembered that due to the difficulty in detecting and diagnosing occlusal caries it is certain that dentists have been inadvertently sealing in caries for decades.

It must be acknowledged that the advisability of sealing over dentinal caries has been questioned. ${ }^{45}$ In this retrospective study, 30 sealants placed on permanent molar teeth judged to be clinically sound at the time of sealing, but which also had radiographically evident dentine caries present at that time, were assessed after a mean interval of 3.4 years. The number of bacteria in sealed surfaces was less than that found in unsealed surfaces. However, the majority (58\%) of the sealed surfaces still contained cariogenic microorganisms. The carious dentine was found to be moist in all cases, rather than dry and leathery, which was taken to indicate caries activity. This study has a number of drawbacks: the selection of cases was retrospective and based on clinical records; there were no definitions of clinically sound, nor who or how many individuals made the original diagnosis.

The recent systematic review concluded that sealants placed over carious lesions reduced bacteria counts, but that low levels of bacteria might persist without compromising the tooth. ${ }^{46}$ The associated guidelines produced by the American Dental Association concluded: 'Sealants are effective in caries prevention and that sealants can prevent the progression of early non-cavitated lesions' or, to paraphrase, 'if in doubt seal., ${ }^{47}$ This means there is no place in modern caries management for the enamel biopsy or fissure investigation as is still suggested by some sources. ${ }^{1,48}$ it is also entirely wrong just to monitor or leave the surface on review, as this inactivity is only likely to lead to caries progression.

Furthermore, the balance of evidence is clearly in favour of sealing non-cavitated occlusal carious lesions, even those with radioluncencies extending up to a third into dentine. ${ }^{9,17,36}$ This decision as with all treatment decisions should be based on a full risk assessment. Therefore the lesions seen in Figures 1 and 5 and Figures 2 and 6 should both be managed by sealing.

Resin sealants are brittle materials and therefore cannot be used over cavitated carious lesions as without the support of the underlying tooth structure they will fracture. Therefore the discussion about sealing over caries refers only to uncavitated carious occlusal surfaces.

All sealants whether preventive or therapeutic should be reviewed at regular intervals to ensure optimal outcome. Defective sealants do not make the surface more caries prone than if the sealant had not been placed but the surface does not benefit from the protection optimal sealant coverage provides. ${ }^{34,49,50}$

The evidence suggests that perhaps one in ten lesions will progress under therapeutic sealants. ${ }^{17,36}$ Most practitioners will use visual inspection hopefully supported by radiographs to monitor surfaces. ${ }^{51}$ Visual monitoring of caries under sealants has been shown to be possible and valid and radiographs offer 


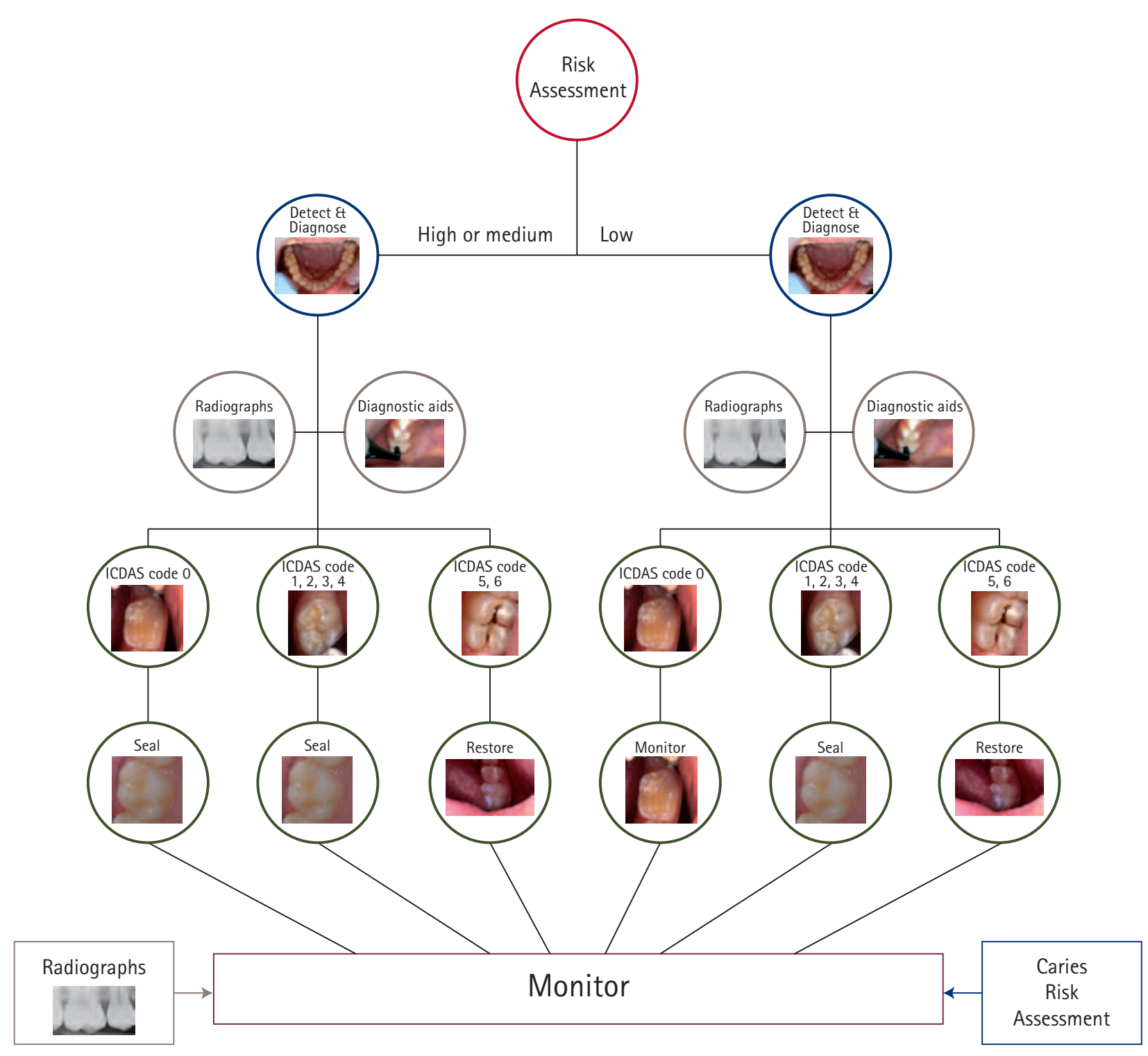

Fig. 10 Management of caries in pits and fissures based on risk assessment and meticulous caries diagnosis (ICDAS)

the opportunity for direct comparison over time. ${ }^{52}$ Of the novel technologies laser fluoresce devices are also of value in this regard as they have been shown to be accurate despite the presence of the sealant and offer the advantage of the opportunity to record the digital reading for future comparison. ${ }^{53}$

Although patients will not return for review, given the balance of risk the placement of a destructive restoration in every patient with questionable caries is not justified. It is vital that the practitioner explains the reasons and need for review to the patient and their carers, so that they understand the need to return for review and this should be recorded in the notes. It should be remembered that restorations also fail.
Figure 10 presents a flow diagram for the management of pits and fissures based on a risk assessment and meticulous caries diagnosis.

\section{CONCLUSION}

In summary, the oral examination should include meticulous caries diagnosis (ICDAS) supported by radiographs as necessary and the results of this examination should be recorded adequately. Sealants are highly effective at caries prevention halving the prevalence of dentinal caries and should be used as the first choice intervention to prevent the progression of non-cavited occlusal carious lesions, rather than restorative management.

\footnotetext{
1. Smallridge J. UK national clinical guidelines in paediatric dentistry: use of fissure sealants
}

including management of the stained fissure in first permanent molars. Int J Paediatr Dent 2010; doi: 10.1111/j.1365-1263X.2009.01035.x.

2. Featherstone J D, Doméjean S. Minimal intervention dentistry: part 1. From 'compulsive' restorative dentistry to rational therapeutic strategies. Br Dent J 2012; 213: 441-445.

3. Pitts N B, Chestnutt I G, Evans D, White D, Chadwick $B$, Steele J G. The dentinal caries experience of children in the United Kingdom, 2003. Br Dent J 2006; 200: 313-320.

4. Brantley C F, Bader J D, Shugars D A, Nesbit S P. Does the cycle of rerestoration lead to larger restorations? J Am Dent Assoc 1995; 126: 1407-1413.

5. Ahovuo-Saloranta A, Hiiri A, Nordblad A, Mäkelä $\mathrm{M}$, Worthington H V. Pit and fissure sealants for preventing dental decay in the permanent teeth of children and adolescents. Cochrane Database Syst Rev 2008; CD001830.

6. Deery C, Fyffe H E, Nugent Z, Nuttall N M, Pitts $\mathrm{N}$ B. A proposed method for assessing the quality of sealants - the CCC Sealant Evaluation System. Community Dent and Oral Epidemiol 2001; 29: 83-91.

7. Soames J V, Southam J C. Oral pathology. 4th ed. Oxford: Oxford University Press, 2005.

8. Fusayama T, Terashima S. Differentiation of two layers of carious dentin by staining. Bull Tokyo Med Dent Univ 1972; 19: 83-92. 
9. Ricketts D N, Ekstrand K R, Kidd E A, Larsen T. Relating visual and radiographic ranked scoring systems for occlusal caries detection to histological and microbiological evidence. Oper Dent 2002 27: 231-237.

10. Holmgren C J, Roux D, Doméjean S. Minimal intervention dentistry: part 5. Atraumatic restorative treatment (ART) - a minimum intervention and minimally invasive approach for the management of dental caries. Br Dent J 2013; 214: 11-18.

11. Nyvad B, Crielaard W, Mira A, Takahashi N, Beighton D. Dental caries from a molecular microbiological perspective. Caries Res 2013; 47: 89-102.

12. Ricketts D N, Kidd E A, Innes N, Clarkson J. Complete or ultraconservative removal of decayed tissue in unfilled teeth. Cochrane Database Syst Rev 2006, CD003808.

13. Tellez M, Gomez J, Pretty I, Ellwood R, Ismail A. Evidence on existing caries risk assessment systems: are they predictive of future caries? Community Dent Oral Epidemio/ 2012; doi: 10.1111/cdoe.12003.

14. Disney J A, Graves R C, Stamm J W, Bohannan H M, Abernathy J R, Zack D D. The University of North Carolina caries risk assessment study: further developments in caries risk prediction. Community Dent Oral Epidemiol 1992; 20: 64-75.

15. Featherstone J D, White J M, Hoover C I et al. A randomized clinical trial of anticaries therapies targeted according to risk assessment (caries management by risk assessment). Caries Res 2012; 46: 118-129.

16. Hänsel Petersson G, Twetman S, Bratthall D. Evaluation of a computer program for caries risk assessment in schoolchildren. Caries Res 2002; 36: 327-340.

17. Ridell $\mathrm{K}, \mathrm{Olsson} \mathrm{H}$, Mejàre I. Unrestored dentin caries and deep dentin restorations in Swedish adolescents. Caries Res 2008; 42: 164-170.

18. Ismail A I, Tellez M, Pitts N B et al. Caries management pathways preserve dental tissues and promote oral health. Community Dent Oral Epidemiol 2013; 41: e12-e40.

19. Ismail A I, Sohn W, Tellez M et al. The International Caries Detection and Assessment System (ICDAS): an integrated system for measuring dental caries. Community Dent Oral Epidemiol 2007; 35: $170-178$.

20. ICDAS Foundation. What is ICDAS? Online informa-

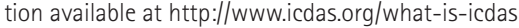
(accessed May 2013)

21. Bonner B C, Bourgeois D M, Douglas G V, Chan K, Pitts N B. The feasibility of data collection in dental practices, using codes for the International Caries Detection and Assessment System (ICDAS), to allow European general dental practitioners to monitor dental caries at local, national and international levels. Prim Dent Care 2011; 18: 83-90.

22. Kay E J, Watts A, Paterson R C, Blinkhorn A S. Preliminary investigation into the validity of dentists' decisions to restore occlusal surfaces of permanent teeth. Community Dent Oral Epidemiol
1988; 16: 91-94.

23. Ekstrand K, Qvist V, Thylstrup A. Light microscope study of the effect of probing in occlusal surfaces. Caries Res 1987; 21: 368-374

24. Loesche W J, Svanberg M L, Pape H R. Intraoral transmission of Streptococcus mutans by a dental explorer. J Dent Res 1979; 58: 1765-1770.

25. Verdonschot $E H$, Bronkhorst E M, Burgersdijk R C, König K G, Schaeken M J, Truin G J. Performance of some diagnostic systems in examinations for small occlusal carious lesions. Caries Res 1992; 26: 59-64.

26. Bader J D, Shugars D A, Bonito A J. A systematic review of the performance of methods for identifying carious lesions. J Public Health Dent 2002; 62: 201-213.

27. Gimeneza T, Bragaa M M, Raggioa D P, Deery C, Ricketts D N, Mendesa F M. Fluorescence-based methods for detecting caries lesions: systematic review, meta-analysis and sources of heterogeneity. PloS One 2013; 8: e60421.

28. Antonson S A, Antonson D E, Brener S et al. Twentyfour month clinical evaluation of fissure sealants on partially erupted permanent first molars: glass ionomer versus resin-based sealant. J Am Dent Assoc 2012; 143: 115-122.

29. Yengopal V, Mickenautsch S. Resin-modified glassionomer cements versus resin-based materials as fissure sealants: a meta-analysis of clinical trials. Eur Arch Paediatr Dent 2010; 11: 18-25.

30. Donnan M F, Ball I A. A double-blind clinical trial to determine the importance of pumice prophylaxis on fissure sealant retention. Br Dent J 1988; 165: 283-286.

31. Thomson J L, Main C, Gillespie F C, Stephen K W. The effect of salivary contamination on fissure sealant-enamel bond strength. J Oral Rehabil 1981 8: 11-18.

32. Hitt J C, Feigal R J. Use of bonding agent to reduce sealant sensitivity to moisture contamination: an in vitro study. Pediatr Dent 1992; 14: 41-46.

33. Burbridge L, Nugent Z, Deery C. A randomised controlled trial of the effectiveness of a one-step conditioning agent in sealant placement: 6 month results. Int J Paediatr Dent 2006; 16: 242-230.

34. Deery C, Fyffe H E, Nugent Z, Nuttall N M, Pitts N B. Integrity, maintenance and caries susceptibility of sealed surfaces in adolescents receiving regular care from general dental practitioners in Scotland. Int J Paediatr Dent 1997; 7: 75-80.

35. Handelman S L, Buonocore M G, Heseck D J. A preliminary report on the effect of fissure sealant on bacteria in dental caries. J Prosthet Dent 1972; 27: 390-392.

36. Handelman S L, Buonocore M G, Schoute P C. Progress report on the effect of a fissure sealant on bacteria in dental caries. J Am Dent Assoc 1973; 87: 1189-1191.

37. Going R E, Loesche W J, Grainger D A, Syed S A. The viability of microorganisms in carious lesions five years after covering with a fissure sealant. J Am
Dent Assoc 1978; 97: 455-462.

38. Handelman S L, Washburn F, Wopperer P. Two-year report of sealant effect on bacteria in dental caries. J Am Dent Assoc 1976; 93: 967-970.

39. Harris N O, Moolenaar L, Hornberger N, Knight $\mathrm{G} H$, Frew R A. Adhesive sealant clinical trial: effectiveness in a school population of the US Virgin Islands. J Prev Dent 1976; 3: 27-37.

40. Gibson G B, Richardson A S. Sticky fissure management. J Can Dent Assoc 1980; 46: 255-258.

41. Jensen $O \mathrm{E}$, Handelman S L. Effect of an autopolymerizing sealant on viability of microflora in occlusal dental caries. Scan J Dent Res 1980: 88: 382-388.

42. Handelman $S \mathrm{~L}$, Leverett D H, Espeland M A, Curzon $J$ A. Clinical radiographic evaluation of sealed carious and sound tooth surfaces. J Am Dent Assoc 1986; 113: 751-754

43. Mertz-Fairhurst E J, Adair S M, Sams D R et al. Cariostatic and ultra conservative sealed restorations: nine-year results among children and adults. J Dent Child 1995; 62: 97-107.

44. Borges B C, de Souza Borges J, Braz R, Montes M A de Assunção Pinheiro I V. Arrest of non-cavitated dentinal occlusal caries by sealing pits and fissures: a 36-month, randomised controlled clinical trial. Int Dent J 2012; 62: 251-255.

45. Weerheijm K L, de Soet J J, van Amerongen W E, de Graaff J. Sealing of occlusal hidden caries lesions: an alternative for curative treatment? ASDC J Dent Child 1992; 59: 263-268.

46. Oong E M, Griffin S O, Kohn W G, Gooch B F Caufield $P$ W. The effect of dental sealants on bacteria levels in caries lesions: a review of the evidence. J Am Dent Assoc 2008; 139: 271-278.

47. Beauchamp J, Caufield P W, Crall J J et al. Evidencebased clinical recommendations for the use of pitandfissure sealants: a report of the American Dental Association Council on Scientific Affairs. J Am Dent Assoc 2008; 139: 257-268.

48. Yip K, Smales R. Oral diagnosis and treatment planning: part 5. Preventive and treatment planning for dental caries. Br Dent J 2012; 213: $211-220$.

49. Chestnutt I G, Schäfer F, Jacobson A P, Stephen K W. The prevalence and effectiveness of fissure sealants in Scottish adolescents. Br Dent J 1994; 177: 125-129.

50. Ismail A I, Gagnon P. A longitudinal evaluation of fissure sealants applied in dental practices. J Dent Res 1995; 74: 1583-1590.

51. Faculty of General Dental Practitioners (UK). Selection criteria for dental radiography. FGDP UK, 2000.

52. Deery C, Fyffe H E, Nugent Z, Nuttall N M, Pitts N B. The effect of placing a clear pit and fissure sealant on the validity and reproducibility of occlusal caries diagnosis. Caries Res 1995; 29: 377-381.

53. Deery C, Illoya J, Nugent Z J, Srinivasan V. The effect of placing a clear sealant on the validity and reproducibility of occlusal caries diagnosis by a laser fluorescence device (DIAGNOdent), an in vitro study. Caries Res 2006; 40: 186-193. 